\title{
Plots, Attacks, and the Measurement of Terrorism*
}

\author{
Thomas Hegghammer ${ }^{\dagger} \quad$ Neil Ketchley
}

1 October 2021

\begin{abstract}
Event datasets are central to the study of terrorism. Political scientists typically use terrorist attacks as the dependent variable and test covariates to identify factors that produce terrorism. But attacks are an imperfect measure of terrorist activity because of "plot attrition" — the tendency for plots to derail due to police intervention or other reasons. Building on recent advances in plot data collection, we show that common research designs predicting terrorist incidents produce statistically significantly different results depending on whether incidents are operationalized as plots or attacks. This is after accounting for state security capability, suggesting plot attrition is dynamic and not easily controlled out. Although not unproblematic, plot data are a better measure of terrorist activity than attack data and should be incorporated, when available, in future studies on the causes of terrorism.
\end{abstract}

Keywords: Terrorism, data, measurement

*We thank Petter Nesser for contributing key data and ideas, Vidar Skretting and Frida Ekren for valuable research assistance, Bjørn Høyland, Anders Ravik Jupskås, Carl Henrik Knutsen, Eirik Lamøy, Jacob Ravndal, and Tore Wig for helpful comments on early drafts, and Martha Crenshaw, Margaret Wilson, and Markus Binder for sharing data. Supplementary information and replication materials are available at https://github.com/Hegghammer/plots.

${ }^{\dagger}$ Norwegian Defence Research Establishment (FFI) - thomas.hegghammer@ffi.no

$\ddagger$ University of Oslo - neil.ketchley@stv.uio.no 


\section{Introduction}

How should we measure terrorism? The answer seems obvious: count the attacks. But attacks are only the subset of terrorist activity that happen to reach execution. Many plots are foiled by police or derail for other reasons, never to enter terrorism datasets. In this article, we build on recent advances in plot data collection to conduct the first systematic examination of this potential measurement problem. We show that, while plots and attacks are often highly correlated, they differ enough to produce statistically different results in common study designs. Answers to the question "what causes terrorism" can therefore vary depending on how we operationalize the notion of terrorist activity.

The inquiry matters because attack counts are central to the study of terrorism. A large proportion of quantitative studies on terrorism measure terrorist activity in executed attacks or its derivatives (such as casualties). Event datasets such as the Global Terrorism Database (LaFree and Dugan 2007) and ITERATE (Mickolus 2007) underpin hundreds of studies into the causes and effects of terrorism. The accuracy of this knowledge hinges on executed attacks being a reasonably valid measure of terrorist activity.

That assumption merits scrutiny because of "plot attrition" — the tendency for terrorist plots to derail prior to execution. Many viable attack plans fail to materialise due to small slip-ups: a sleep-deprived bombmaker causing a premature explosion or an operative that forgets to change the SIM card on her phone. We do not know the 
precise extent of the phenomenon, but studies of jihadi plots in the West have found plot attrition rates in the order of 60 to 70 percent (Crenshaw, Dahl, and Wilson 2017a: 22, 34-35; Sageman 2009: 18). None of this activity is captured in attack counts, suggesting Crenshaw and Lafree (2017: 69) were correct in describing attacks as "the tip of the iceberg" of terrorist activity.

Scholars have studied foiled plots, but not their statistical dimensions. That literature has focused on the history of specific groups (Nesser 2018), the features of the plot preparation process (Cothren et al. 2008; Gruenewald, Klein, Drawve, et al. 2019; E. H. Kaplan 2012) and why some plots fail and others succeed (Gruenewald, Klein, Freilich, et al. 2019; Jackson and Frelinger 2009; McCleskey et al. 2007; K. Strom et al. 2010). Several researchers have noted that attacks can misrepresent terrorist activity (Crenshaw and LaFree 2017: 69; Sageman 2009: 5), but the broader epistemological implications of this observation have not been explored. Meanwhile, the literature on measurement problems in terrorism research has not even noted the problem raised by foiled plots (Dugan and Distler 2016; J. D. Freilich, Chermak, and Gruenewald 2015; J. Freilich and Lafree 2016; Mickolus 2002; Joseph K. Young and Findley 2011).

This article is the first systematic examination the statistical relationship between plots and attacks. While others have explored this relationship for small incident samples, we examine all the available multi-year and multi-country plot datasets in the hope of extracting more generalizeable insights. To do this, we exploit 
recent advances in plot data collection that provide fine-grained data on plots by jihadi groups in the West and on chemical, biological, radiological and nuclear (CBRN) plots worldwide over the last quarter-century. We then conduct two tests: first, we study the association between plot and attack counts in all the datasets; second, we set up a plausible study of jihadi terrorism in Europe and compare how covariates of theoretical interest predict the incidence of plots and attacks. Our central objective is to establish whether the correlates of plots produce different results from the correlates of attacks in large-n studies of terrorism.

We find that they do. The correlation between plots and attacks varies across different units of analysis and functional forms. More importantly, we get statistically significantly different results when predicting the incidence of terrorism, depending on whether we use plot or attack data. The difference persists despite controlling for security spending, suggesting there is no modelling quick fix to the measurement problem. Finally, we show that if scholars want to study the incidence of terrorist attacks, they should consider a two-step process that takes into account the number of plots that failed. Taken together, the findings suggest that plots should be taken seriously as a measure of terrorist activity and that social scientists studying other phenomena should pay attention to precursor events. 


\section{Conceptual framework}

We start by specifying the conceptual relationship between plots and attacks. Since our perspective is new, we describe the prevailing approach to terrorism measurement before presenting our framework.

\subsection{The standard view: Terrorist activity as attacks}

Political scientists have searched for the causes of terrorism with quantitative methods for over forty years (Mickolus 1977). In the now substantial literature, the typical approach consists of examining the statistical relationship between selected covariates and the incidence of terrorism.

Most studies examine country-level variables (Morris and LaFree 2017), and scholars have estimated the effect on terrorism of a long list of factors, notably ${ }^{1}$ :

- Regime type (Aksoy and Carter 2014; Chenoweth 2013; Eskildsen and Bjørnskov 2020; Eubank and Weinberg 2001; Foster, Braithwaite, and Sobek 2013; Gaibulloev, Piazza, and Sandler 2017; Li 2005; James A. Piazza 2007; Savun and Phillips 2009; Joseph K. Young and Dugan 2011)

- Economic conditions (Blomberg, Hess, and Weerapana 2004; Boehmer and Daube 2013; Caruso and Schneider 2011; Freytag et al. 2011; Gries, Krieger, and Meierrieks 2011; Keefer and Loayza 2008; Li and Schaub 2004; Meierrieks

\footnotetext{
${ }^{1}$ This list is not exhaustive. Other studies examine more specific factors, while yet others explore batteries of dozens of covariates in search of terrorism's causes (Gassebner and Luechinger 2011; Kis-Katos, Liebert, and Schulze 2011; Krieger and Meierrieks 2011).
} 
and Gries 2013)

- Poverty and inequality (Abadie 2006; Bravo and Dias 2006; Burgoon 2006; Enders and Hoover 2012; James A. Piazza 2006; James A. Piazza 2011)

- Migration and ethnicity (Basuchoudhary and II 2010; Böhmelt and Bove 2020b; Bove and Böhmelt 2016; Choi and Salehyan 2013; Helbling and Meierrieks 2020; Milton, Spencer, and Findley 2013)

- State capacity (Carter 2016; Coggins 2015; Danzell and Zidek 2013; Daxecker and Hess 2013; Dreher and Fischer 2010; George 2018; Lai 2007; Newman 2007; James A. Piazza 2008b; Tikuisis 2009)

- Political stability (Campos and Gassebner 2013; Fahey and LaFree 2015; Schumacher and Schraeder 2019)

- Foreign policy (Kattelman 2020; Neumayer and Plümper 2009; Plümper and Neumayer 2010)

- Domestic policy (Koch and Cranmer 2007; Kurrild-Klitgaard, Justesen, and Klemmensen 2006; Walsh and Piazza 2010) and

- Culture (Böhmelt and Bove 2020a; Gelfand et al. 2013).

This literature is not marginal; it arguably represents the dominant approach to the study of terrorism in political science. Unlike qualitative studies, which tend to appear in specialist terrorism journals, country-year correlation studies have featured in the leading journals of political science and economics, and have attracted thousands of citations. 
Practically all these studies measure the incidence of terrorism in attacks only. They frequently refer to the dependent variable as "terrorism" - implying "terrorist activity" - but operationalize it exclusively as counts of executed attacks. Most do not control for measures of counterterrorism capacity, suggesting that plot attrition has not been a theoretical concern. The existing literature has effectively elided terrorist activity and executed terrorist attacks.

Moreover, the metrics used in many other quantitative research designs are derivatives of attack counts. Suicide terrorism, for example, is studied as a subset of executed attacks (Choi and Piazza 2014; Michael C. Horowitz 2010; Pape 2003; James A. Piazza 2008a; Wade and Reiter 2007). Casualty counts are necessarily based on consummated attacks (Asal and Rethemeyer 2008; Asal, Brown, and Schulzke 2015; Sánchez-Cuenca 2009). Group-level tactical preferences are usually inferred from distributions of executed attacks (Abrahms and Potter 2015; Brandt and Sandler 2010; Brown 2020; Michael C. Horowitz, Perkoski, and Potter 2018), and spatial diffusion of terrorism likewise (Braithwaite and Li 2007; Neumayer and Plümper 2010; Polo 2020). Some studies that take individuals as the unit of analysis - to study what makes people become terrorists - also draw their sample from attack perpetrators (Lankford and Hakim 2011; Weinberg, Pedahzur, and Canetti-Nisim 2003).

Not all quantitative studies use dependent variables derived from attacks. Many individual-level studies examine group, movement, or plot participants (Bakker 2006; Krueger 2007; Lee 2011), thus sampling beyond just attack perpetrators. Some 
country-level designs include terrorist group emergence (Chenoweth 2010) or group fate (Carter 2012) as outcome variables. But in the overwhelming majority of quantitative terrorism studies, the dependent variable is executed attacks or a derivative of it.

The existing approach to terrorism measurement is arguably based on an implicit understanding of a terrorism production chain with three ideal-type stations: causes, agents, and activity (see Figure 1). First are the underlying causes, typically operationalized as societal features such as regime type or GDP. Second are the agents, who emerge due to the contextual factors and instigate the violence; they are usually studied through group traits such as ideology or organizational structure. Third is the resulting violent activity, nearly always operationalized as executed attacks. It is this last "activity box" that we wish to unpack.

Figure 1: The terrorism production chain as commonly conceptualized

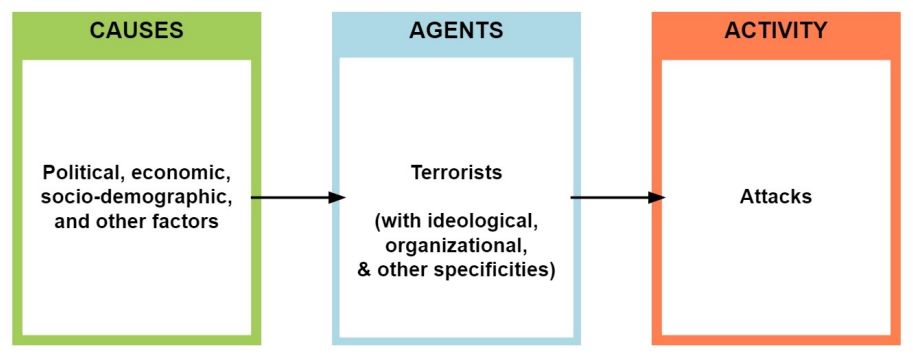


Figure 2: The terrorism production chain, disaggregated

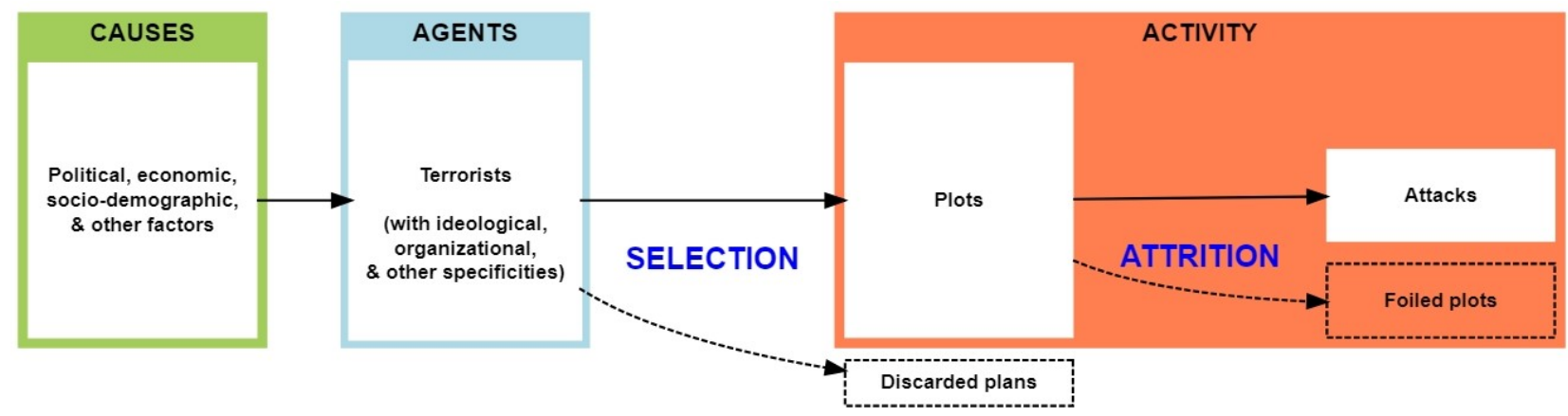

\subsection{Our suggestion: Terrorist activity as attacks and plots}

We propose to widen the notion of terrorist activity to include both plots and attacks. Given the well-documented phenomenon of plot derailment, attack counts must underreport terrorist activity at least some of the time. We therefore suggest conceptualizing plots as an event type that can be used to measure terrorist activity alongside attack counts.

We posit that all terrorist attacks require at least some degree of preparation; i.e., that they are preceded by a process that takes an operational idea from the abstract to the tangible. At some point in the process, the operational plan will become sufficiently specific and viable to be considered a "plot." A plot is an operational plan that is developed enough to produce an attack absent any subsequent external intervention.

Not all aspirations become executed attacks. A scaling off occurs, whereby some plans are discarded, prevented, or botched before reaching execution. Multiple factors contribute to the scaling off, but we distinguish between two ideal types of mechanisms 
- choices and externalities - and divide the production chain correspondingly into two stages. First is the selection stage, where terrorists evaluate operational ideas based on feasibility, discarding some and pursuing others. The latter become plots. Second is the attrition stage, where terrorists try to turn the plots into attacks, only to see some fail for unanticipated reasons, such as police intervention, technical problems, or mistakes. Figure 2 visualises our reconceptualization of the terrorism production chain.

Plots are thus events on a par with attacks, but they provide a different measure of terrorist activity. Plot counts reflect the gross activity level, while attack counts measure the net. The gross level is of scientific interest because it represents the pre-treatment version of the phenomenon at hand. The net level, by contrast, has been reduced by counterterrorism and other intervening factors. Plots are not a perfectly pristine measure of terrorist activity, because terrorism is a strategic game in which countermeasures probably affect terrorists' choices about which plots to pursue. Still, plot counts are less contaminated by intervening variables than attack counts.

Given that all attacks were once plots, we see no reason why plot counts would not be generated by the same causal processes - and thus be drawn from the same underlying distribution - as attacks. The only thing that distinguishes plot production from attack production is the late-stage intervening factors that foil plots. These intervening variables are of theoretical interest, but they can only be studied if we know the gross activity level. When we regress attack counts on broad country 
features such as GDP, as most studies do, we have no way of distinguishing between motivational and constraint-based determinants.

A final reason to study plots is that the plot attrition rate - the percentage of plots in a given place-time unit that fail to reach execution - appears to vary in time and space. Crenshaw et al (2017b: 34-35) found the attrition rate for jihadi

plots in nine Western countries between 2010 and 2016 to vary between 38 and 89 percent across countries and between 47 to 93 percent across years. Strom et al (2015: 8) found that, for terrorism in the USA from 1995 to 2012, the yearly attrition rate varied between 10 and 100 percent.

We currently know little about the determinants of this variation, and herein lies the potential for a measurement problem. If the rate varies in ways we cannot account for, then we cannot infer the gross activity level from the attack count. To return to the iceberg analogy, we face tips of icebergs without knowing how much ice is below the waterline.

\section{Plot data}

While the notion of plot may be conceptually intuitive, it is less obvious how it can be used to generate reliable data about terrorist activity. The fundamental problem is observability: while attacks cause damage in public, plots are unconsummated intentions. We contend that plots can still be observed because they need to leave the realm of thought in at least one of two ways: verbal articulation and practical 
preparation. We therefore operationalize the term plot as 1) a plan to deploy violence 2) of which a key feature has been verbally articulated and 3) for which observable preparatory steps have been taken.

In practice, it can be hard to identify plots consistently. Given the range of tactical possibilities in terrorism, there are no hard-and-fast rules for what constitutes a compromising statement or preparatory step, which leaves room for interpretation. Foiled plots attract less media attention than attacks, leaving less of a reporting trail for dataset-builders to follow, especially when the plot is foiled covertly and those involved do not go to trial. Public information on alleged foiled plot cases is vulnerable to biases such as media sensationalism and selective leaks from government investigators. Moreover, the availability of reliable case evidence depends on the existence of trustworthy police, independent judiciaries, and a free media. In authoritarian countries, information regarding alleged plots cannot be trusted. To these plot-specific problems must be added the general challenges faced by compilers of incident data, such as geographical and chronological reporting biases. There are unquestionably more potential sources of noise in plot data than in attack data.

We still argue that systematic plot data are not fundamentally elusive, just difficult to obtain. In some contexts, such as Western democracies in the digital age, the amount of open source information about political activism is so substantial that reasonably reliable plot data can be generated. But they are more labor-intensive to compile than attack datasets, and some areas and time periods might never be 
covered for lack of reliable sources. This is why existing plot data have tended to cover limited time periods and areas.

Recently, however, three much larger datasets have become available. These are Nesser's (2020) data on jihadi plots in Western Europe 1994-2019 (henceforth "Nesser"), Crenshaw et al's (2017a) data on jihadi plots in the West 1993-2017 (henceforth "Crenshaw"), and the POICN (Binder and Ackerman 2019) dataset on CBRN plots worldwide 1990-2017 (henceforth "POICN"). Together, they form the universe of available plot datasets that cover multiple years and countries. $^{2}$

We consider all three datasets relatively reliable because they were compiled by academics who used largely the same procedures as other incident datasets and who discussed their inclusion criteria in depth (see Appendix). We trust POICN despite its coverage of authoritarian countries because CBRN incidents attract special international scrutiny. The data generation process for plot data and attack data is the same as far as the collection procedure is concerned, although there may be slight differences in their respective sets of reporting biases.

We recognize that plot data are imperfect, but their flaws must be put in perspective. Global attack datasets are known to contain severe geographical reporting

${ }^{2}$ Existing plot datasets typically cover a single type of terrorism in a single country: ADL (2018), Beutel (2012), Bjelopera and Randol (2010), Bromund and Roach (2009), Heritage (2018), Jenkins (2017), Mueller (2019), and Simcox et al. (2011). Some cover a single type in several countries but over short timespans (3-15 years): Bakker (2006), Boyd and Dunn (2008), Beuze (2017), HSC (2016), Jenkins (2006), Sageman (2009), and Simcox (2017). A few cover all terrorism over long timespans but in a single country: ATS (2018), ECDB (2019), and K. J. Strom, Hollywood, and Pope (2015). Another (Dahl (2011)) covers the world over 23 years but for a very narrow type (jihadi terrorism directed at US targets). We considered including Ravndal, Jupskås, and Bjørgo (2020), which covers far-right terrorism in Europe since 1990, but its plot inclusion criteria are stricter than those of our three datasets, making comparison difficult. 
biases - with underreporting of terrorism in non-Western countries sometimes reaching 98 percent - yet scholars have been happy to use them. ${ }^{3}$ Whatever reporting biases exist in plot data from contemporary Western democracies, they are almost certainly less severe than this.

In the following, we use Nesser, Crenshaw, and POICN to study the relationship between plots and attacks. Each dataset codes for execution, thus providing us with both plot and attack counts. ${ }^{4}$ We examine the plot-attack relationship internal to each dataset and compare the results across them. For all their limitations, these datasets offer the best available basis to explore the plot-attack relationship.

\section{The relationship between plots and attacks}

As suggested, attack data can underestimate terrorist activity. Given the difficulty of collecting plot data, the question is whether these two measures even out when many events are aggregated across space and time.

Figure 3 shows the relationship between plots and attacks when assigned to different units of analysis. Associations are estimated using Pearson's r correlation coefficient. Aggregating to the country produces the strongest associations, ranging from .94 to .88 . Note, however, that the association between launched attacks and plots

\footnotetext{
${ }^{3}$ For example, Behlendorf, Belur, and Kumar (2016) compared GTD data with local police data from a region in India and found that GTD recorded only two percent of the terrorist attacks recorded by police. A similar study on Turkey found that GTD only contained three percent of the attacks recorded by local authorities (Cubukcu and Forst 2018).

${ }^{4}$ We cleaned and reprocessed the datasets to make them comparable; see the Appendix for details.
} 
varies considerably - to as low as . 22 - when examining the across-country association on a year-by-year basis (see Figures A4.1-4.3). We also find strong associations when aggregating to the year: across the three datasets, Pearson's r ranges between .96 and .82. This has positive implications for descriptive studies that aggregate attack counts to large geographic or temporal units.

Figure 3: Bivariate correlations by units of analysis
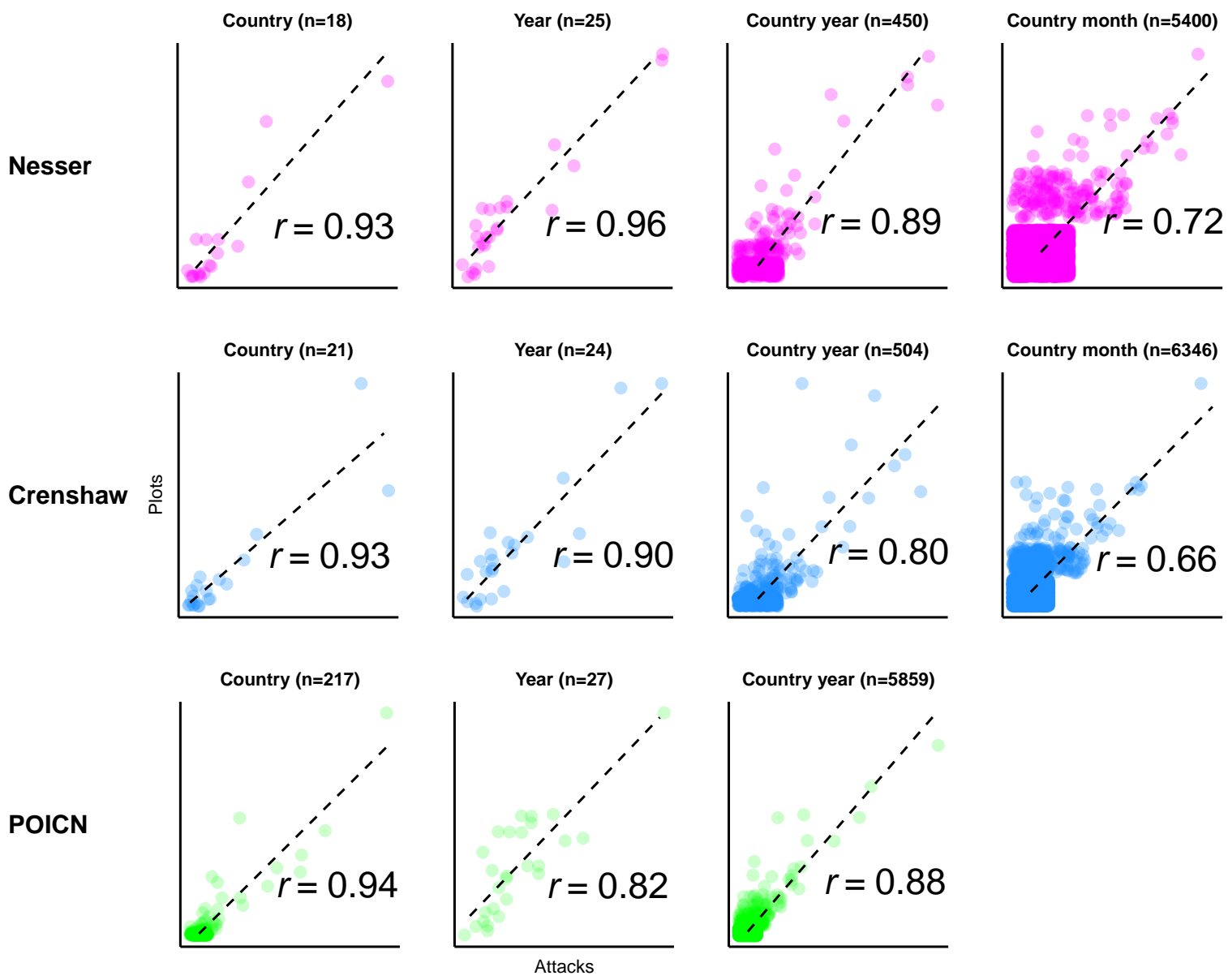

The relationship between launched attacks and plots is attenuated when observing different countries over multiple units of time. When assigned to the country year, the typical observation in quantitative studies of terrorism, launched attacks 
and plots remain strongly positively correlated, but the association now ranges from .89 to .80. Disaggregation to smaller units of time attenuates the association further. Confining attention to Nesser and Crenshaw's datasets, which allow for assignment to the country month, Pearson's r reduces to .72 and .66. Temporal disaggregation is important. Researchers often want to capture the effects of time-varying covariates e.g. the impact of government policies on the incidence of terrorism at $t+1$. But as our bi-variate correlations show, attacks provide only a rough approximation of the intensity of terrorist activity in a country at a given point in time.

Another relevant consideration relates to functional form. Terrorism is a rare event: most countries will see few if any attacks or plots in a given year. In consequence, both launched attacks and plots follow heavy-tailed distributions; the modal observation is zero, while most events are concentrated in just a few units (see Figure A5 for histograms). To minimize the influence of outliers, applied researchers often look to reduce the size of this tail by using different functional forms. Figure 4 shows how the association between launched attacks and plots in a country year varies by taking the square root, incrementing and taking the log, and transforming to the inverse hyperbolic sine. The relevant comparison is the unbounded count of events in a country year reported in Figure 3. In all three datasets, transformation further attenuates the correlation between launched attacks and plots by between 3 and 10 percent, as compared to an unbounded count. Applied researchers are also often interested in examining how the incidence of terrorism compares across spatial 
units that vary by population. Taking the per capita rate, we see that the correlation between launched attacks and plots is further weakened in the Nesser and POICN datasets, while it is strengthened in Crenshaw.

Figure 4: Bivariate correlations by functional form
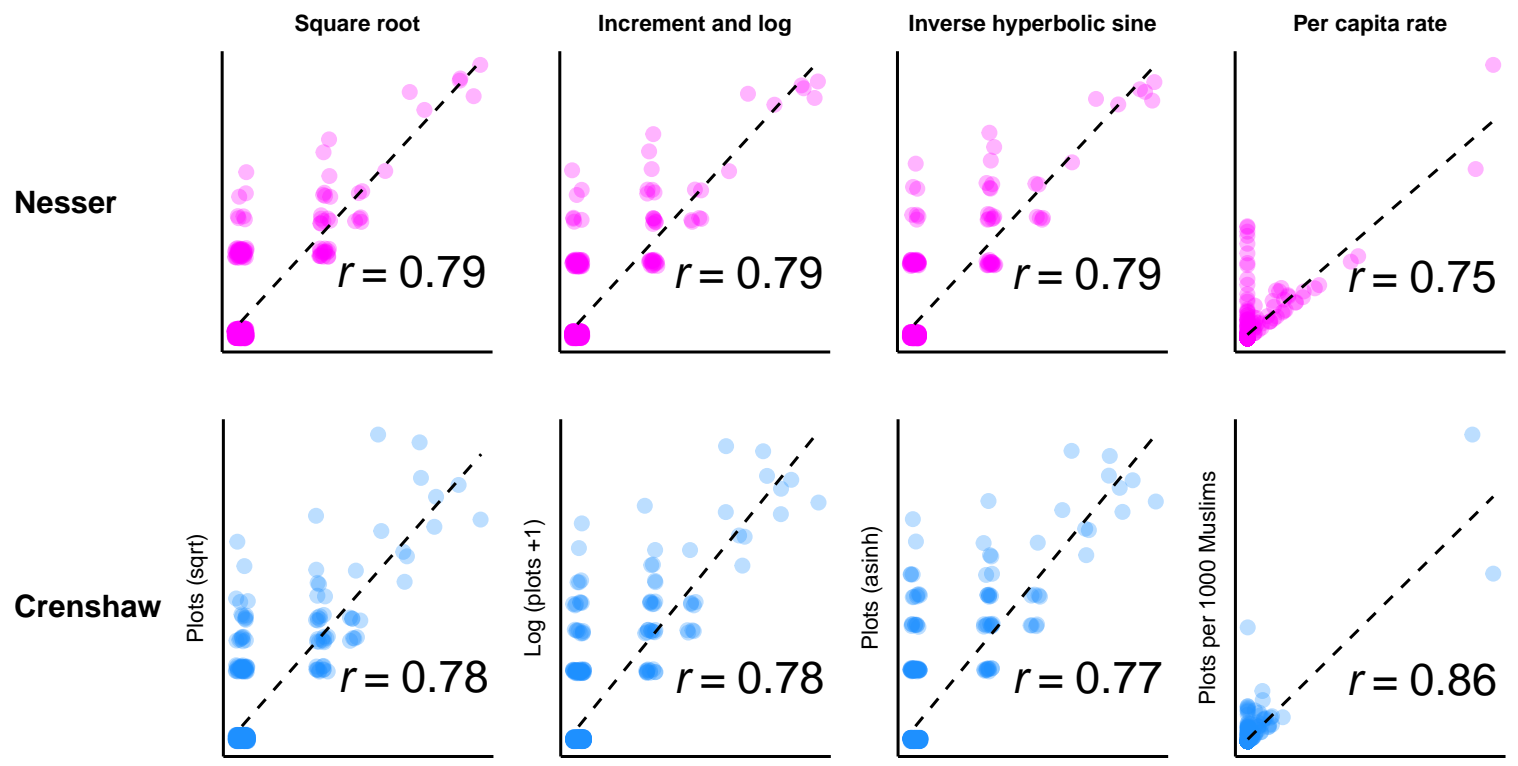

POICN
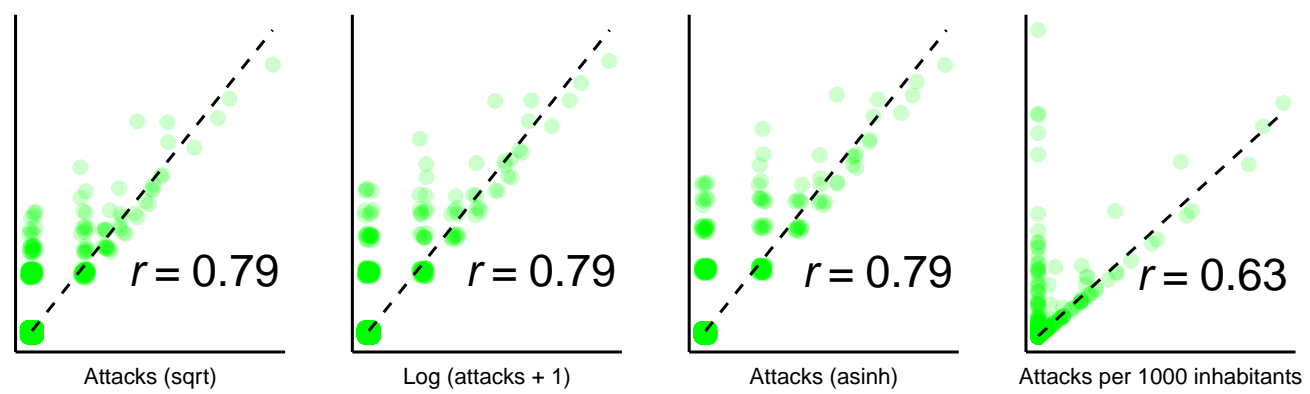

An alternative comparison examines the differences between launched attacks and plots when estimated as count processes. Here, the key statistic is the mean of the count of launched attacks and plots when assigned to their country year. Figure 5 provides an illustration, using the observed means from our three datasets to simulate their respective Poisson and negative binomial distributions. While there is overlap, it 
is clear that taking launched attacks as the outcome measure will tend to overpredict the number of country years with zero instances of terrorist activity, and underpredict country years with one or more terrorist events.

\section{$5 \quad$ Predicting terrorism}

Does the choice between plots and launched attacks make a difference in practice? To find out, we mock replicate a plausible study of jihadism in Europe. The reason we do not replicate a published analysis is that there are no studies whose empirical scope matches that of the available plot data. We choose jihadism in Europe because we consider the Nesser dataset to be the most reliable of the three plot datasets. It also has the highest plot-attack correlation and so offers the toughest test for the proposition that attack and plot data are not interchangeable.

We choose our covariates following the literature on the causes of terrorism described earlier, with some adaptations for the region and actor type under consideration. We exclude regime type (since we study Western Europe), and we add population size and time trend variables. See Table A6 for an overview of covariates and their data sources. All except one of the variables are assumed in the literature to operate on the motivation side of the terrorism production chain, i.e., as grievances suspected of increasing the intention to use terrorism. As such, they should affect plot and attack production similarly. One of our variables, security spending, represents a constraint and should capture plot attrition if the latter is merely a function of 
Figure 5: Poisson and negative binomial distributions of expected counts (overlaid bars)
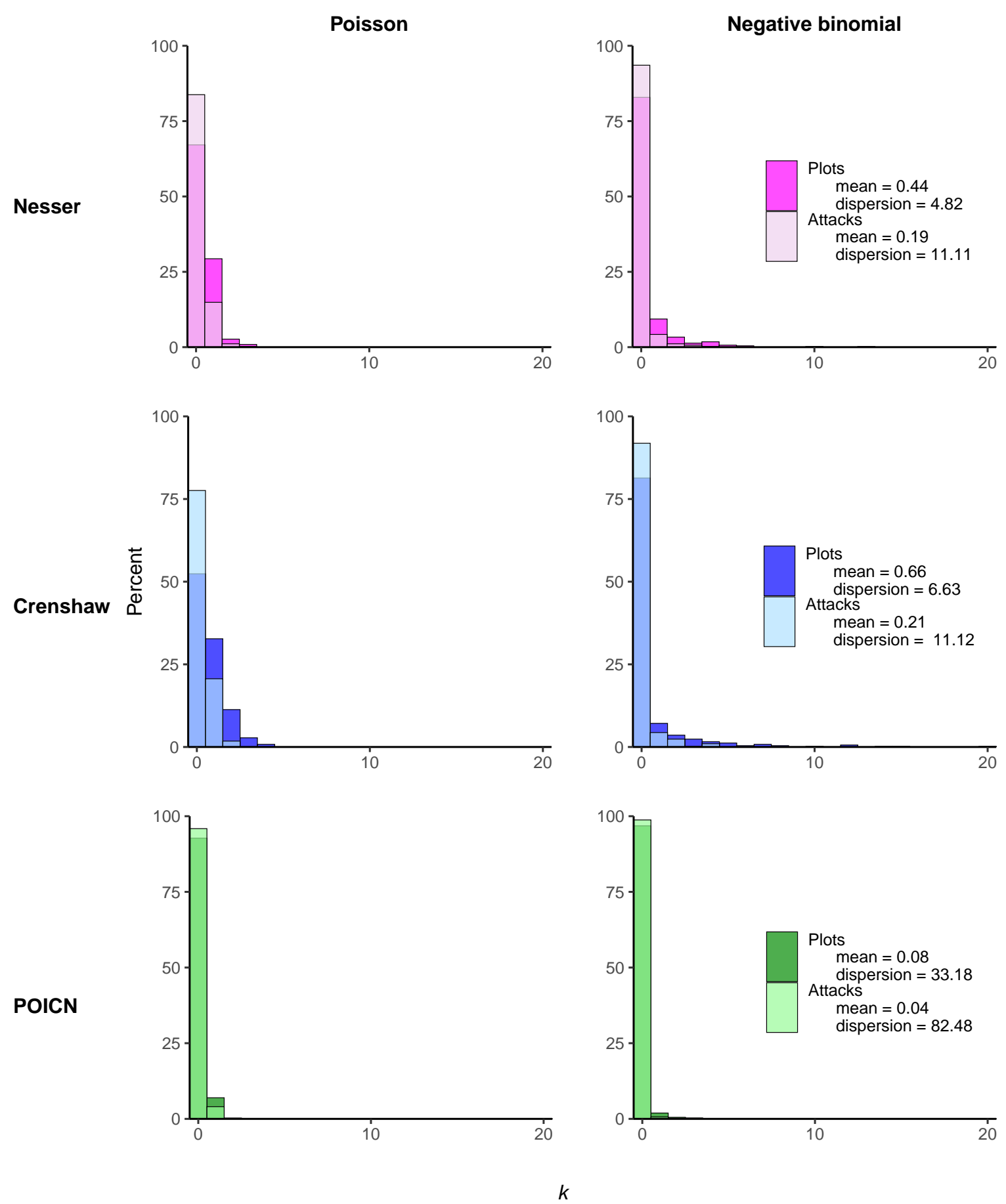
counterterrorism capacity.

To model the incidence of events, we analyze the counts of plots and attacks using a cross-sectional, time-series structure. We choose this relatively straightforward and common design precisely because it is widespread. To model this, we follow Wooldridge (1999) and use Poisson regression. Here, the count of plots in country $(i)$ at year $(t)$ is estimated as:

$$
\text { plots }_{i t}=\exp \left(\text { plots }_{i t-1}+\sum \beta_{k} X_{k i t-1}+\delta_{k} T_{k i t}+\alpha_{i}\right)
$$

where plots $_{i t-1}$ is the lagged number of plots in a country the previous year, $X_{k}$ is a vector of time-varying, country-level covariates lagged by one year, with $\beta_{k}$ their coefficients, and $T_{k}$ is a vector of variables capturing time trends related to $9 / 11$ and the rise of ISIS, with their coefficients, $\delta_{k}$, to be estimated. The regression equation for attacks follows that of equation (1) where the count of attacks is estimated as:

$$
\text { attacks }_{i t}=\exp \left(\text { attacks }_{i t-1}+\sum \beta_{k} X_{k i t-1}+\delta_{k} T_{k i t}+\alpha_{i}\right)
$$

but where attacks $s_{i t-1}$ is the lagged number of attacks in the previous year, and $X_{k}$ and $T_{k}$ are the same vectors of covariates. Empty models point to the importance of between-country differences in patterning the incidence of both outcomes. ${ }^{5}$

\footnotetext{
${ }^{5}$ Note that the estimated degree of between-country heterogeneity is sensitive to how terrorist activity is operationalized; the intraclass correlation for launched attacks is .23, while for plots it is .46. One implication is that taking attacks as the dependent variable underestimates the importance of differences between countries in explaining terrorism.
} 
We therefore include country-level intercepts, $\alpha_{i}$, resulting in a Poisson fixed effects model. These intercepts absorb the unique time-invariant characteristics of each country. When interpreting covariates, e.g. the number of refugees, we are thus measuring change in the number of refugees within a country over time. Standard errors are clustered on the country.

We report the results in Table 1. In interpreting our findings, we take instruction from Gelman and Stern (2006) and test the equality of coefficients to see whether the estimated associations are statistically significantly different from one another (as opposed to being statistically different from zero), depending on how terrorism is operationalized. The results of these tests are denoted in the table by the chi-squared statistic $\left(\chi^{2}\right)$.

We see that an increase in plots the previous year is a positive and significant predictor of plots the following year. However, having more attacks at $t-1$ is significantly negatively associated with attacks the next year, and the difference between these associations is itself statistically significant. Increasing a country's population is a significant and positive predictor of plots; however, the coefficient again changes sign when taking attacks as the outcome, albeit without approaching statistical significance. Crucially, these associations are statistically significantly different from one another. Increasing the percentage of the population who are Muslim is positively associated with plots, but negatively associated with attacks — and the chi-squared statistic indicates that these relationships are also drawn from different distributions. Increasing 
Table 1: Predicting the incidence of jihadi terrorism

\begin{tabular}{|c|c|c|c|}
\hline & \multicolumn{3}{|c|}{ Poisson fixed effects } \\
\hline & DV: Plots & DV: Attacks & $\chi^{2}$ \\
\hline Lagged DV (asinh, t-1) & $\begin{array}{l}0.217^{*} \\
(0.123)\end{array}$ & $\begin{array}{c}-0.487^{* * *} \\
(0.130)\end{array}$ & $46.76^{* * *}$ \\
\hline Population (log, t-1) & $\begin{array}{c}6.075 \\
(5.192)\end{array}$ & $\begin{array}{l}-21.354 \\
(14.242)\end{array}$ & $5.29^{* *}$ \\
\hline Muslims $(\%, \mathrm{t}-1)$ & $\begin{array}{c}0.061 \\
(0.246)\end{array}$ & $\begin{array}{l}-0.348 \\
(0.318)\end{array}$ & $4.78^{* *}$ \\
\hline Refugees (log, t-1) & $\begin{array}{l}-0.401 \\
(0.322)\end{array}$ & $\begin{array}{l}-0.072 \\
(0.428)\end{array}$ & 0.74 \\
\hline GDP per capita (log, t-1) & $\begin{array}{l}-1.655^{*} \\
(0.887)\end{array}$ & $\begin{array}{l}-0.761 \\
(2.032)\end{array}$ & 0.24 \\
\hline Unemployment $(\%, \mathrm{t}-1)$ & $\begin{array}{c}-0.118^{* * *} \\
(0.046)\end{array}$ & $\begin{array}{c}-0.145^{* *} \\
(0.057)\end{array}$ & 0.23 \\
\hline CPI change $(\%, \mathrm{t}-1)$ & $\begin{array}{l}-0.061 \\
(0.118)\end{array}$ & $\begin{array}{c}0.020 \\
(0.226)\end{array}$ & 0.31 \\
\hline Social spending (\% GDP, t-1) & $\begin{array}{c}0.028 \\
(0.090)\end{array}$ & $\begin{array}{c}0.213^{* *} \\
(0.094)\end{array}$ & $4.12^{* *}$ \\
\hline Left/right government (log, t-1) & $\begin{array}{l}-0.238 \\
(0.427)\end{array}$ & $\begin{array}{c}-1.107^{* *} \\
(0.535)\end{array}$ & $8.82^{* * *}$ \\
\hline Security budget (\% GDP, t-1) & $\begin{array}{l}1.163^{*} \\
(0.657)\end{array}$ & $\begin{array}{l}-1.321 \\
(1.165)\end{array}$ & $7.33^{*}$ \\
\hline Troops in Muslim countries (asinh, t-1) & $\begin{array}{c}0.580 * * \\
(0.284)\end{array}$ & $\begin{array}{c}1.086^{* * *} \\
(0.285)\end{array}$ & $3.32^{*}$ \\
\hline Right wing attacks (sqrt, t-1) & $\begin{array}{c}0.009 \\
(0.082)\end{array}$ & $\begin{array}{c}0.461^{* *} \\
(0.225)\end{array}$ & $4.18^{* *}$ \\
\hline Years from 2001 & $\begin{array}{l}0.314^{*} \\
(0.188)\end{array}$ & $\begin{array}{c}0.897^{* *} \\
(0.381)\end{array}$ & $4.53^{* *}$ \\
\hline Years from 2001 (squared) & $\begin{array}{l}-0.015 \\
(0.013)\end{array}$ & $\begin{array}{c}-0.040^{*} \\
(0.023)\end{array}$ & $3.21^{*}$ \\
\hline Years from ISIS caliphate & $\begin{array}{c}1.375^{* * *} \\
(0.488)\end{array}$ & $\begin{array}{c}2.748^{* * *} \\
(0.812)\end{array}$ & $5.91^{* *}$ \\
\hline Years from ISIS caliphate (squared) & $\begin{array}{c}-0.266^{* * *} \\
(0.066)\end{array}$ & $\begin{array}{c}-0.409 * * * \\
(0.111)\end{array}$ & $2.95^{*}$ \\
\hline Country fixed intercepts & $\checkmark$ & $\checkmark$ & \\
\hline Country years & 394 & 394 & \\
\hline
\end{tabular}

the number of refugees in a country is not statistically associated with either plots or attacks, and we cannot reject the null that the differences between the coefficients is zero. 
Turning to economic explanations: increasing GDP per capita reduces the incidence of plots - but we cannot reject the null hypothesis of no association with regards to attacks. The difference between these associations is also not distinguishable from zero. Unemployment reduces the incidence of both plots and attacks, and there is no difference between the coefficients. Increasing the cost of living reduces the incidence of plots, while the coefficient for attacks is also negative. The difference between the coefficients is again not significant at conventional levels. Social spending reduces the number of plots, but increases the number of attacks, and this difference is statistically significant.

Looking at state characteristics, having a more right wing government seems to significantly and substantively reduce the incidents of attacks, but not plots, and this difference is statistically significant. Importantly, increasing a country's security budget is significantly positively associated with the number of plots in a given year, while it reduces the number of attacks - and the difference is again statistically significant.

Perhaps unsurprisingly, countries with more troops in Muslim-majority countries suffer more plots. We find a similar relationship with attacks, but the size of the association is much larger, and this difference is again statistically significant. Increasing the level of right wing violence seems to increase the number of attacks, but not plots, and the coefficients are statistically significantly different at $\mathrm{p}<.05$.

Finally, both plots and attacks seem to increase and then decrease in the years 
following $9 / 11$, as indicated by the squared term. We find a similar, non-monotonic relationship for the years following ISIS' declaration of a caliphate. Again, the strengths of these associations are highly sensitive to how terrorism is operationalized.

In the Appendix we test different estimators (negative binomial regression and OLS) and functional forms (see Table A7.1). We also extend the analysis to the Crenshaw dataset (see Table A7.2). Across all models, we find meaningful statistical differences between how our covariates predict the incidence of terrorism depending on how terrorist activity is measured.

\section{Country years with zero terrorist attacks}

Of course, there may be good reasons to study the number of terrorist attacks in a given unit time. In this mode, attacks are a measure of successful violence, rather than a proxy for terrorist activity. However, as we have argued, country years with zero attacks may not equate to country years with zero plots. It follows that country years with zero attacks may not be "true zeros" - we cannot observe an attack, because one or more plots have failed.

In such cases, country years with zeros (i.e., there was no attack recorded) may be generated by a separate process from the count of attacks. To test for this, we draw on the Nesser dataset of jihadi attacks in Europe and re-run the models above using zero-inflated Poisson regression. The dependent variable is the count of attacks in a country year. In the first stage we use the transformed count of failed 
Table 2: Predicting country years with zero jihadi attacks

\begin{tabular}{|c|c|}
\hline & $\begin{array}{c}\text { Zero-inflated Poisson } \\
\text { DV: Attacks }\end{array}$ \\
\hline Lagged DV (asinh, t-1) & $\begin{array}{c}-0.540^{*} \\
(0.284)\end{array}$ \\
\hline Population $(\log , t-1)$ & $\begin{array}{c}0.014 \\
(0.312)\end{array}$ \\
\hline Muslims $(\%, \mathrm{t}-1)$ & $\begin{array}{c}0.294 \\
(0.240)\end{array}$ \\
\hline Refugees (log, t-1) & $\begin{array}{l}-0.257 \\
(0.271)\end{array}$ \\
\hline GDP per capita $(\log , t-1)$ & $\begin{array}{c}0.148 \\
(1.483)\end{array}$ \\
\hline Unemployment $(\%, \mathrm{t}-1)$ & $\begin{array}{l}-0.113 \\
(0.079)\end{array}$ \\
\hline CPI change $(\%, \mathrm{t}-1)$ & $\begin{array}{l}-0.188 \\
(0.262)\end{array}$ \\
\hline Social spending (t-1) & $\begin{array}{l}0.097^{*} \\
(0.055)\end{array}$ \\
\hline Left/right government (log, t-1) & $\begin{array}{l}-0.284 \\
(0.833)\end{array}$ \\
\hline Troops in Muslim countries (asinh, t-1) & $\begin{array}{c}0.767^{* * *} \\
(0.176)\end{array}$ \\
\hline Right wing attacks (sqrt, t-1) & $\begin{array}{c}0.349 \\
(0.236)\end{array}$ \\
\hline Security budget (t-1) & $\begin{array}{c}0.215 \\
(1.271)\end{array}$ \\
\hline Years from 2001 & $\begin{array}{c}0.615 \\
(0.405)\end{array}$ \\
\hline Years from 2001 (squared) & $\begin{array}{l}-0.039 \\
(0.034)\end{array}$ \\
\hline Years from ISIS caliphate & $\begin{array}{c}2.620^{* * *} \\
(0.993)\end{array}$ \\
\hline Years from ISIS caliphate (squared) & $\begin{array}{c}-0.353^{* * *} \\
(0.089)\end{array}$ \\
\hline \multicolumn{2}{|l|}{ Logistic regression } \\
\hline Foiled plots (asinh) & $\begin{array}{c}-0.771^{* * *} \\
(0.217)\end{array}$ \\
\hline Lagged DV (asinh, t-1) & $\begin{array}{l}-2.103 \\
(1.600)\end{array}$ \\
\hline Security budget (t-1) & $\begin{array}{l}-1.209 \\
(1.493)\end{array}$ \\
\hline Country years & 394 \\
\hline
\end{tabular}


plots in a country year, along with the security spending variable and the transformed count of successful attacks the previous year. The covariates in the Poisson portion of the model follow those set out in Table 1. It is not straightforward to estimate a zero-inflated fixed effects model, and so we use a simple panel with standard errors clustered on the country.

The results are reported in Table 2. To enable comparison between the logistic and the Poisson components of the model, we leave coefficients unexponentiated. Confining attention to the first step, we find empirical support for the claim that plot attrition reduces the likelihood of seeing any attacks in a country year. Increasing security spend and the number of successful attacks is negatively associated with seeing an attack the following year, albeit without attaining statistical significance. Crucially, increasing the number of foiled plots in a given year is a substantive and significant predictor of observing zero attacks that same year $(\mathrm{p}<.001)$.

Taken together, these results suggest that when predicting the number of launched attacks, we should consider the possibility that failed plots lead to censoring on the dependent variable - and that this can be accounted for in a zero-inflated process. Should this approach be extended to studying terrorist activity more broadly, thus allowing us to retain attacks as the outcome measure? We think not. A two-step modeling approach can only differentiate between country years with zero or more than zero attacks, whereas we are often interested in country years that see multiple plots, some of which fail and some of which get through. If the number of failed 
plots is known, then taking all plots as the outcome variable is likely to be a superior measure of terrorist activity.

\section{Conclusion}

This article has highlighted an understudied measurement problem at the heart of the study of terrorism. Attacks are an imperfect measure of terrorist activity, because they mask the number of plots that nearly reached execution. As we have shown, analyzing

plot and attack counts yield statistically different results in common research designs, including for consequential covariates related to economic factors, demographics, state characteristics, political grievances, and events. The findings matter little for studies of the effects of terrorism, but have potentially important implications for how we study its causes.

Controlling for counterterrorism capacity does not solve the problem. For one thing, there are few available measures for counterterrorism capacity. Conceptually it is not clear which measures might represent it, and it is practically difficult to get reliable data from the intelligence domain. In our test, one of the best available measures, domestic security spending, did not account for all the plot attrition. For another, there is probably a game-theoretic element to plotting, whereby terrorists will adapt to increased foil risk by initiating fewer plots. Strong counterterrorism may thus produce both high attrition through interception and low attrition through deterrence. We suspect that attrition is partly rooted in plotters' misjudgment of risk, which in 
turn may stem from information problems about their operating environment. This takes us into a fast-paced, micro-level territory which probably cannot be modelled with the data available to academics today.

We see three mitigation strategies. One is for quantitative terrorism scholars to robustness-check their findings against available plot data. Another solution, as it applies to modeling successful attacks, is to account for the determinants of plot attrition with a view to accounting for them in the first step of a zero-inflated count process. The third and ideal solution is to build larger plot datasets and study the causes of terrorism with plots as the dependent variable. We realise that the creation of a plot equivalent of the GTD is unrealistic, but there is low-hanging fruit, such as data on plots by non-jihadi groups in OECD countries.

Our findings have broad social scientific relevance, because the plot-attack relationship has analogies in many other domains. Think planned coups, attempted murders, or infection cases; like plots, they are precursor events to more eye-catching phenomena such as actual coups, homicides, and death by disease (S. Kaplan 1990). In some fields, precursors are studied as a matter of course, because they are understood to contain important information. For example, no serious epidemiologist would measure the spread of a disease only by fatality counts, because the quality of healthcare varies between countries. Social scientists may gain from including precursors or near-miss events more systematically in their analyses.

The implications go even wider, because terrorist activity measurement 
underpins much of what is done and said about terrorism in our societies. Governments design and calibrate counterterrorism policies with at least an eye on hard data. Analysts assess threat levels using metrics of recent activity. And journalists describe terrorist trends invoking current events, while the public worries — or not — based on their perception of the same trends. All should resist the inclination to equate terrorist activity with executed attacks. Sometimes the things that do not happen are as important as those that do.

\section{Bibliography}

Abadie, Alberto. 2006. "Poverty, Political Freedom, and the Roots of Terrorism." American Economic Review 96 (2): 50-56.

Abrahms, Max, and Philip BK Potter. 2015. "Explaining Terrorism: Leadership Deficits and Militant Group Tactics." International Organization, 311-42.

ADL. 2018. "A Homegrown Threat: Islamist Extremist Plots in the United States." New York, NY: Anti-Defamation League.

Aksoy, Deniz, and David B Carter. 2014. "Electoral Institutions and the Emergence of Terrorist Groups." British Journal of Political Science, 181-204.

Asal, Victor, Mitchell Brown, and Marcus Schulzke. 2015. "Kill Them All—Old and Young, Girls and Women and Little Children' 1: An Examination of the Organizational Choice of Targeting Civilians." Political Science Research and Methods 3 (3): 589-607. 
Asal, Victor, and R Karl Rethemeyer. 2008. "The Nature of the Beast: Organizational Structures and the Lethality of Terrorist Attacks." The Journal of Politics 70 (2): $437-49$.

ATS. 2018. "The American Terrorism Study." Fayetteville, AR: University of Arkansas. https://terrorismresearch.uark.edu/data.

Bakker, Edwin. 2006. "Jihadi Terrorists in Europe." The Hague: Netherlands Institute of International Relations.

Basuchoudhary, Atin, and William F. Shughart II. 2010. "On Ethnic Conflict and the Origins of Transnational Terrorism." Defence and Peace Economics 21 (1): 65-87. Behlendorf, Brandon, Jyoti Belur, and Sumit Kumar. 2016. "Peering Through the Kaleidoscope: Variation and Validity in Data Collection on Terrorist Attacks." Studies in Conflict \& Terrorism 39 (7-8): 641-67.

Beutel, Alejandro J. 2012. "Data on Post-9/11 Terrorism in the United States." Washington, DC: Muslim Public Affairs Council.

Beuze, Canelle. 2017. "Terrorist Attacks, Failed Attacks and Plots in the West Linked to the Syrian Iraqi Context (2013-2016)." Paris: Center for the Analysis of Terrorism.

Binder, Markus K, and Gary A Ackerman. 2019. "Pick Your POICN: Introducing the Profiles of Incidents Involving CBRN and Non-State Actors (POICN) Database." Studies in Conflict \& Terrorism, 1-25.

Bjelopera, Jerome P, and Mark A. Randol. 2010. "American Jihadist Terrorism: 
Combating a Complex Threat." Washington, DC: Congressional Research Service.

Blomberg, S. Brock, Gregory D. Hess, and Akila Weerapana. 2004. "Economic Conditions and Terrorism." European Journal of Political Economy, The Economic Consequences of Terror, 20 (2): 463-78. https://doi.org/10.1016/j.ejpoleco.2004. 02.002 .

Boehmer, Charles, and Mark Daube. 2013. "The Curvilinear Effects of Economic Development on Domestic Terrorism." Peace Economics, Peace Science and Public Policy 19 (3): 359-68.

Bove, Vincenzo, and Tobias Böhmelt. 2016. "Does Immigration Induce Terrorism?" Journal of Politics 78 (2): 572-88.

Boyd, Dallas, and Lewis A. Dunn. 2008. "Why Have We Not Been Attacked Again? Competing and Complementary Hypotheses for Homeland Attack Frequency." Alexandria, VA: Defense Threat Reduction Agency.

Böhmelt, Tobias, and Vincenzo Bove. 2020a. "Does Cultural Proximity Contain Terrorism Diffusion?" Journal of Peace Research 57 (2): 251-64.

— 2020b. "How Migration Policies Moderate the Diffusion of Terrorism." European Journal of Political Research 59 (1): 160-81.

Braithwaite, Alex, and Quan Li. 2007. "Transnational Terrorism Hot Spots: Identification and Impact Evaluation." Conflict Management and Peace Science 24 (4): 281-96.

Brandt, Patrick T., and Todd Sandler. 2010. "What Do Transnational Terrorists 
Target? Has It Changed? Are We Safer?" Journal of Conflict Resolution 54 (2): $214-36$.

Bravo, Ana Bela Santos, and Carlos Manuel Mendes Dias. 2006. "An Empirical Analysis of Terrorism: Deprivation, Islamism and Geopolitical Factors." Defence and Peace Economics 17 (4): 329-41.

Bromund, Ted R, and Morgan L Roach. 2009. Islamist Terrorist Plots in Great Britain: Uncovering the Global Network. Heritage Foundation.

Brown, Joseph M. 2020. "Correlates of Warning: Territory, Democracy, and Casualty Aversion in Terrorist Tactics." International Organization 74 (2): 396-415.

Burgoon, Brian. 2006. "On Welfare and Terror: Social Welfare Policies and PoliticalEconomic Roots of Terrorism." Journal of Conflict Resolution 50 (2): 176-203.

Campos, Nauro F., and Martin Gassebner. 2013. "International Terrorism, Domestic Political Instability, and the Escalation Effect." Economics 83 Politics 25 (1): $27-47$.

Carter, David B. 2012. "A Blessing or a Curse? State Support for Terrorist Groups." International Organization, 129-51.

—. 2016. "Provocation and the Strategy of Terrorist and Guerrilla Attacks." International Organization, 133-73.

Caruso, Raul, and Friedrich Schneider. 2011. "The Socio-Economic Determinants of Terrorism and Political Violence in Western Europe (1994-2007).” European Journal of Political Economy 27 (December): S37-49. 
Chenoweth, Erica. 2010. "Democratic Competition and Terrorist Activity." The Journal of Politics 72 (1): 16-30.

_ 2013. "Terrorism and Democracy." Annual Review of Political Science 16 (1): $355-78$.

Choi, Seung-Whan, and James A. Piazza. 2014. "Internally Displaced Populations and Suicide Terrorism." Journal of Conflict Resolution, October.

Choi, Seung-Whan, and Idean Salehyan. 2013. "No Good Deed Goes Unpunished: Refugees, Humanitarian Aid, and Terrorism." Conflict Management and Peace Science 30 (1): 53-75.

Coggins, Bridget L. 2015. "Does State Failure Cause Terrorism? An Empirical Analysis (1999-2008)." Journal of Conflict Resolution 59 (3): 455-83.

Cothren, Jackson, Brent L Smith, Paxton Roberts, and Kelly R Damphousse. 2008. "Geospatial and Temporal Patterns of Preparatory Conduct Among American Terrorists." International Journal of Comparative and Applied Criminal Justice 32 (1): $23-41$.

Crenshaw, Martha, Erik Dahl, and Margaret A. Wilson. 2017a. "Comparing Failed, Foiled, Completed and Successful Terrorist Attacks: Year 5 Final Report." College Park, MD: National Consortium for the Study of Terrorism; Responses to Terrorism. - 2017b. "Jihadist Terrorist Plots in the United States." START Research Brief. https://www.start.umd.edu/pubs/START_JihadistTerroristPlotsUS_Dec2017.p df. 
Crenshaw, Martha, and Gary LaFree. 2017. "The Tip of the Iceberg: Accounting for Failed and Foiled Terrorist Plots." In Countering Terrorism, 69-98. Washington DC: Brookings Institution Press.

Cubukcu, Suat, and Brian Forst. 2018. "Measuring Terrorism." Homicide Studies 22 (1): 94-116.

Dahl, Erik J. 2011. "The Plots That Failed: Intelligence Lessons Learned from Unsuccessful Terrorist Attacks Against the United States." Studies in Conflict $\mathcal{E}$ Terrorism 34 (8): 621-48.

Danzell, Orlandrew E., and Steve Zidek. 2013. "Does Counterterrorism Spending Reduce the Incidence and Lethality of Terrorism? A Quantitative Analysis of 34 Countries." Defense 63 Security Analysis 29 (3): 218-33.

Daxecker, Ursula E, and Michael L Hess. 2013. "Repression Hurts: Coercive Government Responses and the Demise of Terrorist Campaigns." British Journal of Political Science, 559-77.

Dreher, Axel, and Justina A. V. Fischer. 2010. "Government Decentralization as a Disincentive For Transnational Terror? An Empirical Analysis." International Economic Review 51 (4): 981-1002.

Dugan, Laura, and Michael Distler. 2016. "Measuring Terrorism." In The Handbook of the Criminology of Terrorism, edited by Gary LaFree and Joshua D. Freilich, 189-205. Hoboken, NJ: Wiley-Blackwell.

ECDB. 2019. "United States Extremist Crime Database." College Park, MD: National 
Consortium for the Study of Terrorism; Responses to Terrorism. https://www.star t.umd.edu/research-projects/united-states-extremist-crime-database-ecdb19902010.

Enders, Walter, and Gary A. Hoover. 2012. "The Nonlinear Relationship Between Terrorism and Poverty." American Economic Review 102 (3): 267-72.

Eskildsen, Lasse Skjoldager, and Christian Bjørnskov. 2020. "Does Freedom of Expression Cause Less Terrorism?" Political Studies, 0032321720950223.

Eubank, W., and L. Weinberg. 2001. "Terrorism and Democracy: Perpetrators and Victims." Terrorism and Political Violence 13 (1): 155-64.

Fahey, Susan, and Gary LaFree. 2015. "Does Country-Level Social Disorganization Increase Terrorist Attacks?" Terrorism and Political Violence 27 (1): 81-111.

Foster, Dennis M, Alex Braithwaite, and David Sobek. 2013. "There Can Be No Compromise: Institutional Inclusiveness, Fractionalization and Domestic Terrorism." British Journal of Political Science, 541-717.

Freilich, Joshua D., Steven M. Chermak, and Jeff Gruenewald. 2015. "The Future of Terrorism Research: A Review Essay." International Journal of Comparative and Applied Criminal Justice 39 (4): 353-69.

Freilich, Joshua, and Gary Lafree. 2016. "Measurement Issues in the Study of Terrorism: Introducing the Special Issue." Studies in Conflict \& Terrorism 39 (7): $569-79$.

Freytag, Andreas, Jens J. Krüger, Daniel Meierrieks, and Friedrich Schneider. 2011. 
"The Origins of Terrorism: Cross-Country Estimates of Socio-Economic Determinants of Terrorism." European Journal of Political Economy, Special issue:Terrorism, 27 (December): S5-16.

Gaibulloev, Khusrav, James A. Piazza, and Todd Sandler. 2017. "Regime Types and Terrorism." International Organization 71 (3): 491-522.

Gassebner, Martin, and Simon Luechinger. 2011. "Lock, Stock, and Barrel: A Comprehensive Assessment of the Determinants of Terror." Public Choice 149 (3): 235.

Gelfand, Michele J., Gary LaFree, Susan Fahey, and Emily Feinberg. 2013. "Culture and Extremism." Journal of Social Issues 69 (3): 495-517.

George, Justin. 2018. "State Failure and Transnational Terrorism: An Empirical Analysis." Journal of Conflict Resolution 62 (3): 471-95.

Gries, Thomas, Tim Krieger, and Daniel Meierrieks. 2011. "Causal Linkages Between Domestic Terrorism and Economic Growth." Defence and Peace Economics 22 (5): 493-508.

Gruenewald, Jeff, Brent R Klein, Grant Drawve, Brent L Smith, and Katie Ratcliff. 2019. "Suspicious Preoperational Activities and Law Enforcement Interdiction of Terrorist Plots." Policing: An International Journal.

Gruenewald, Jeff, Brent R Klein, Joshua D Freilich, and Steven Chermak. 2019. "American Jihadi Terrorism: A Comparison of Homicides and Unsuccessful Plots." Terrorism and Political Violence 31 (3): 516-35. 
Helbling, Marc, and Daniel Meierrieks. 2020. "Terrorism and Migration: An Overview." British Journal of Political Science, 1-20.

Heritage. 2018. "Terror Plot 104 Targets the Fourth of July." Washington, DC: Heritage Foundation. https://\%20www.heritage.org/terrorism/commentary/terro r-plot-104-targets-the-fourth-july.

Horowitz, Michael C. 2010. "Nonstate Actors and the Diffusion of Innovations: The Case of Suicide Terrorism." International Organization, 33-64.

Horowitz, Michael C., Evan Perkoski, and Philip B. K. Potter. 2018. "Tactical Diversity in Militant Violence." International Organization 72 (1): 139-71.

HSC. 2016. "\#Terror Gone Viral: Overview of the 75 ISIS-Linked Plots Against the West, 2014 - 2016." Washington, DC: House Homeland Security Committee.

Jackson, Brian A, and David R Frelinger. 2009. "Understanding Why Terrorist Operations Succeed or Fail." RAND.

Jenkins, Brian Michael. 2006. "Unconquerable Nation: Knowing Our Enemy, Strengthening Ourselves." Santa Monica, CA: RAND.

— 2017. "The Origins of America's Jihadists." Santa Monica, CA: RAND.

Kaplan, Edward H. 2012. "Estimating the Duration of Jihadi Terror Plots in the United States." Studies in Conflict \& Terrorism 35 (12): 880-94.

Kaplan, Stan. 1990. "On the Inclusion of Precursor and Near Miss Events in Quantitative Risk Assessments: A Bayesian Point of View and a Space Shuttle Example." Reliability Engineering 6 System Safety 27 (1): 103-15. 
Kattelman, Kyle T. 2020. "Assessing Success of the Global War on Terror: Terrorist Attack Frequency and the Backlash Effect." Dynamics of Asymmetric Conflict 13 (1): $67-86$.

Keefer, Philip, and Norman Loayza. 2008. Terrorism, Economic Development, and Political Openness. Cambridge: Cambridge University Press.

Kis-Katos, Krisztina, Helge Liebert, and Günther G. Schulze. 2011. "On the Origin of Domestic and International Terrorism." European Journal of Political Economy 27 (December): S17-36.

Koch, Michael T., and Skyler Cranmer. 2007. "Testing the 'Dick Cheney' Hypothesis: Do Governments of the Left Attract More Terrorism Than Governments of the Right?" Conflict Management and Peace Science 24 (4): 311-26.

Krieger, Tim, and Daniel Meierrieks. 2011. "What Causes Terrorism?" Public Choice $147(1): 3-27$.

Krueger, Alan B. 2007. What Makes a Terrorist? Economics and the Roots of Terrorism. Princeton: Princeton University Press.

Kurrild-Klitgaard, Peter, Mogens K. Justesen, and Robert Klemmensen. 2006. "The Political Economy of Freedom, Democracy and Transnational Terrorism." Public Choice 128 (1/2): 289-315.

LaFree, Gary, and Laura Dugan. 2007. "Introducing the Global Terrorism Database." Terrorism and Political Violence 19 (2): 181-204.

Lai, Brian. 2007. "'Draining the Swamp': An Empirical Examination of the Production 
of International Terrorism, 1968-1998." Conflict Management and Peace Science 24 (4): $297-310$.

Lankford, Adam, and Nayab Hakim. 2011. "From Columbine to Palestine: A Comparative Analysis of Rampage Shooters in the United States and Volunteer Suicide Bombers in the Middle East." Aggression and Violent Behavior 16 (2): $98-107$.

Lee, Alexander. 2011. "Who Becomes a Terrorist?: Poverty, Education, and the Origins of Political Violence." World Politics 63: 203-45.

Li, Quan. 2005. "Does Democracy Promote or Reduce Transnational Terrorist Incidents?" The Journal of Conflict Resolution 49 (2): 278-97.

Li, Quan, and Drew Schaub. 2004. "Economic Globalization and Transnational Terrorism: A Pooled Time-Series Analysis." Journal of Conflict Resolution 48 (2): $230-58$.

McCleskey, Edward, Diana McCord, Jennifer Leetz, and John Markey. 2007. "Underlying Reasons for Success and Failure of Terrorist Attacks: Selected Case Studies." Homeland Security Institute.

Meierrieks, Daniel, and Thomas Gries. 2013. "Causality Between Terrorism and Economic Growth.” Journal of Peace Research 50 (1): 91-104.

Mickolus, Edward F. 1977. "Statistical Approaches to the Study of Terrorism." In Terrorism - Interdisciplinary Perspectives, edited by Yonah Alexander, Hans J. Morgenthau, and Seymour Maxwell Finger, 209-69. New York, NY: John Jay 
Press.

—. 2002. "How Do We Know We're Winning the War Against Terrorists? Issues in Measurement." Studies in Conflict \& Terrorism 25 (3): 151-60.

—. 2007. International Terrorism: Attributes of Terrorist Events. Vinyard Software, 2006 [producer]. Dunn Loring, VA.

Milton, Daniel, Megan Spencer, and Michael Findley. 2013. "Radicalism of the Hopeless: Refugee Flows and Transnational Terrorism." International Interactions 39 (5): $621-45$.

Morris, Nancy A., and Gary LaFree. 2017. "Country-Level Predictors of Terrorism." In The Handbook of the Criminology of Terrorism, 93-117. Chichester: WileyBlackwell.

Mueller, John. 2019. "Terrorism Since 9/11: The American Cases." The Educational Publisher. https://politicalscience.osu.edu/faculty/jmueller/since.pdf.

Nesser, Petter. 2018. Islamist Terrorism in Europe. Oxford: Oxford University Press.

—. 2020. "Introducing the Jihadi Plots in Europe Dataset (JPED)." Draft Manuscript.

Neumayer, Eric, and Thomas Plümper. 2009. "International Terrorism and the Clash of Civilizations." British Journal of Political Science, 711-34.

—. 2010. "Galton's Problem and Contagion in International Terrorism Along Civilizational Lines." Conflict Management and Peace Science 27 (4): 308-25.

Newman, Edward. 2007. "Weak States, State Failure, and Terrorism." Terrorism and 
Political Violence 19 (4): 463-88.

Pape, Robert. 2003. "The Strategic Logic of Suicide Terrorism." American Political Science Review 97: 343-61.

Piazza, James A. 2006. "Rooted in Poverty?: Terrorism, Poor Economic Development, and Social Cleavages." Terrorism and Political Violence 18 (1): 159-77.

- 2007. "Draining the Swamp: Democracy Promotion, State Failure, and Terrorism in 19 Middle Eastern Countries." Studies in Conflict 83 Terrorism 30 (6): $521-39$.

—. 2008a. "A Supply-Side View of Suicide Terrorism: A Cross-National Study." The Journal of Politics 70 (1): 28-39.

— . 2008b. "Incubators of Terror: Do Failed and Failing States Promote Transnational Terrorism?" International Studies Quarterly 52 (3): 469-88.

Piazza, James A. 2011. "Poverty, Minority Economic Discrimination, and Domestic Terrorism." Journal of Peace Research 48 (3): 339-53.

Plümper, Thomas, and Eric Neumayer. 2010. "The Friend of My Enemy Is My Enemy: International Alliances and International Terrorism.” European Journal of Political Research 49 (1): 75-96.

Polo, Sara M. T. 2020. "How Terrorism Spreads: Emulation and the Diffusion of Ethnic and Ethnoreligious Terrorism." Journal of Conflict Resolution 64 (10): $1916-42$.

Ravndal, Jacob Aasland, Anders Ravik Jupskås, and Tore Bjørgo. 2020. "RTV Trend 
Report 2020: Right-Wing Terrorism and Violence in Western Europe, 1990 - 2019." Oslo: Center for Research on Extremism.

Sageman, Marc. 2009. "Confronting Al-Qaeda: Understanding the Threat in Afghanistan." Perspectives on Terrorism 3 (4): 4-25.

Savun, Burcu, and Brian J. Phillips. 2009. "Democracy, Foreign Policy, and Terrorism." The Journal of Conflict Resolution 53 (6): 878-904.

Sánchez-Cuenca, Ignacio. 2009. "Revolutionary Dreams and Terrorist Violence in the Developed World: Explaining Country Variation." Journal of Peace Research 46 (5): 687-706.

Schumacher, Michael J., and Peter J. Schraeder. 2019. "Does Domestic Political Instability Foster Terrorism? Global Evidence from the Arab Spring Era (2011-14)." Studies in Conflict \& Terrorism 0 (0): 1-25.

Simcox, Robin. 2017. "European Islamist Plots and Attacks Since 2014-and How the u.s. Can Help Prevent Them." Washington, DC: Heritage Foundation.

Simcox, Robin, Hannah Stuart, Houriyah Ahmed, and Douglas Murray. 2011. "Islamist Terrorism: The British Connections." London: Henry Jackson Society.

Strom, Kevin J, John S Hollywood, and Mark W Pope. 2015. "Terrorist Plots the United States: What We Have Really Faced, and How We Might Best Defend Against It." Santa Monica, CA: RAND.

Strom, Kevin, John Hollywood, Mark Pope, Garth Weintraub, Crystal Daye, and Don Gemeinhardt. 2010. "Building on Clues: Examining Successes and Failures 
in Detecting US Terrorist Plots, 1999-2009.” Institute for Homeland Security Solutions, 621-48.

Tikuisis, Peter. 2009. "On the Relationship Between Weak States and Terrorism." Behavioral Sciences of Terrorism and Political Aggression 1 (1): 66-79.

Wade, Sara Jackson, and Dan Reiter. 2007. "Does Democracy Matter? Regime Type and Suicide Terrorism." The Journal of Conflict Resolution 51 (2): 329-48.

Walsh, James I., and James A. Piazza. 2010. "Why Respecting Physical Integrity Rights Reduces Terrorism." Comparative Political Studies 43 (5): 551-77.

Weinberg, Leonard, Ami Pedahzur, and Daphna Canetti-Nisim. 2003. "The Social and Religious Characteristics of Suicide Bombers and Their Victims." Terrorism and Political Violence 15 (3): 139-53.

Wooldridge, Jeffrey M. 1999. "Distribution-Free Estimation of Some Nonlinear Panel Data Models." Journal of Econometrics 90 (1): 77-97.

Young, Joseph K., and Michael G. Findley. 2011. "Promise and Pitfalls of Terrorism Research.” International Studies Review 13 (3): 411-31.

Young, Joseph K, and Laura Dugan. 2011. "Veto Players and Terror." Journal of Peace Research 48 (1): 19-33. 